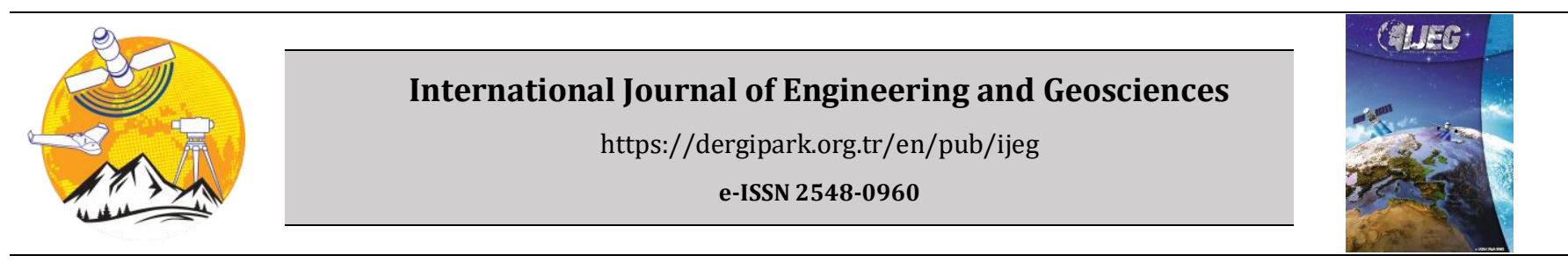

\title{
Evaluating bank erosion and identifying possible anthropogenic causative factors of Kirtankhola River in Barishal, Bangladesh: an integrated GIS and Remote Sensing approaches
}

\author{
Shaikh Ashikur Rahman ${ }^{* 1}$, Md. Muzahidul Islam ${ }^{\circledR}$, Md. Abdullah Salman1® , Muhammad Risalat Rafiq1® \\ ${ }^{1}$ University of Barishal, Department of Geology and Mining, Barishal, Bangladesh
}

\section{Keywords}

Remote sensing

Riverbank erosion

Anthropogenic factors

Meandering

GIS

\begin{abstract}
In Bangladesh, riverbank erosion has turned into one of the most frequently occurring natural disasters, and it affects the socio-economic and livelihood status as well as the environment of the adjoining areas. Kirtankhola River in Barishal, is this kind of river. This study assesses the amount of erosion-accretion, examines river profile, detecting key anthropogenic factors behind it, and signifying channel shifting of the river within 10 years (from 2009 to 2019). The study used Landsat Satellite imageries, geospatial techniques, and a semi-structured questionnaire survey throughout the study area. The study showed that erosion dominants at the left bank of river (17.1 ha/year), whereas the accretion rate is higher at the right (19.72 ha/year). Besides, cross-section at selected points of the river providing an evident indication of the river widening thus river course shifting. According to $61 \%$ of the participants in the questionnaire, high waves generated through water vehicles are the main culprit for this extensive erosion. The number of launches has increased significantly within the studied timeperiod, and most of the launches run over $30 \mathrm{~km} / \mathrm{h}$ velocity, where it should be less than $20 \mathrm{~km} / \mathrm{h}$. The study explored a mechanism of how centrifugal force produced by water vehicles increases the intensity of riverbank erosion in the meandering area.
\end{abstract}

\section{INTRODUCTION}

River is one of the most common geomorphological features in Bangladesh. Here, almost seven percent of the total land is covered by rivers (Hasan et al. 2018). The livelihood of the local people of the country vastly depends on these rivers (Khan et al. 2014). Therefore, the rivers are a blessing for the people of Bangladesh; however, this blessing often turns into a curse when it comes to bank erosion. In Bangladesh no other natural disaster is as devastating as riverbank erosion (Khan et al. 2014). Around one million inhabitants are losing their home per year and even they have to leave their village due to large-scale bank erosion (Mahmud et al. 2020). This frequently happening bank erosion takes tolls less in lives but more responsible for the immense quantity of land consumption, demography dislocation, and landlessness (Rabbi et al. 2013). Though the shifting of river courses is a natural phenomenon, it becomes a disaster when considered from the perspective of human settlements. Even though bank erosion is mostly controlled by morphological structure, vegetation cover, bending of the channel, and discharge water (Mazumdar and Talukdar 2018). Kirtankhola River is a distributary of the Mighty Meghna. Sustainability and development of the Barishal Sadar is often threatened by intensive bank erosion. This phenomenon has been acute in recent years. Since 2009, it has already consumed about 320 hectares of land in the study area and a huge amount of land is at high risk. The Barishal City is located on the bank of the Kritankhola River, which flows through the Active Ganges Delta where the uppermost section consists of recently deposited Holocene sediments (Umitsu 1993). Because of unconsolidated recent deltaic sediments, the banks of the Kirtankhola River are highly vulnerable to 
bank consumption (Hasan et al. 2018). High instream siltation is also accelerating the bank erosion activity (Hohensinner et al. 2018). Anthropogenic factors sometimes have more influence in particular areas (Nahar 2015).

From the perspective of Barishal, Kirtankhola plays a crucial role in the transportation system connecting Barishal to different parts of Bangladesh through waterways. The second-largest inland river port is on the bank of it. Every day, numerous cargoes, launches, and speed boats run through the river. Those vehicles produce large hydraulic waves continuously. Nanson et al. (1994); Oswalt and Strauser (1983) postulated that boat-induced waves play an important role to erode river bank. Except on very large-scale rivers, boatgenerated waves have notably greater influence than wind waves (Nanson et al. 1994). The meandering shape of the river in the selected study area is responsible for the excessive centrifugal force of boatgenerated hydraulic waves which then hammer on the cut bank of the river. Regular hitting by waves upon the unprotected banks is facilitating bank erosion. Moreover, cutting down trees for making settlements and sand extraction for the landfill as well as soil excavation for brickfields are also increasing the intensity of bank consumption. Local communities are usually dependent on this river for their livelihood. Rigorous bank erosion in Kirtankhola disappearing roads, schools, houses, croplands, and rural markets. On the other hand, accreted land is not being well distributed among depreciated people. Along with this, poor navigability of the river is also disrupting the busiest river traffic system.

Previous studies had been conducted mostly on bank migration and subsequent socio-economic impacts due to riverbank erosion of major rivers in Bangladesh (Mahmud et al. 2020; Billah 2018; Hasan et al. 2018; Hassan and Akhtaruzzaman 2010; Islam and Rashid 1970; Nahar 2015). A few studies had been carried out on the Kirtankhola River, however, most of these concentrated on the flow pattern and velocity distribution according to the depth as well as geotechnical analysis (Hasan et al. 2018; Ahmed and Afrin 2016). Nevertheless, none of these studies incorporated anthropogenic factors particularly strong centrifugal forces induced by robust hydraulic waves propagated by a wide range of vessels which are accelerating severe bank erosion in the Kirtankhola River.

All over the world, different methods are used for assessing riverbank erosion (Mazumdar and Talukdar 2018), quantifying erosion (Sarkar et al. 2012), and identifying causative factors of erosion (Thakur et al. 2012). However, all those techniques are costly, timeconsuming, and sometimes difficult to do properly rather than using new GIS and RS methods (Mahmud et al. 2020 and Salman et al. 2018). Most of the GIS and RS methods are easy to perform and cost-efficient and receiving great interest in recent times (Joshi et al. 2002). An NDWI method has been performed to depict river channel shifting within the selected time period. Surfer software has been used to identify the changes of channel shape. An unstructured questionnaire survey was conducted in the villages along both sides of Kirtankhola and identified three unions, Charmonai, Charbaria and Charkawa respectively upstream to downstream, where bank erosion is prominent. Secondary data acquired from satellite images, government websites, journals, news articles, and books. The primary objectives of this study are (1) calculating the total erosion and accretion as well as rates over the study period (2) identifying the potential anthropogenic key factors (3) delineating the most vulnerable points in terms of bank consumption (4) illustrating the elevation profiles as well as overall cross-section changes of the river and (5) demonstrating the channel movement in the study area.

\section{STUDY AREA}

The Kirtankhola is a meandering river; the local socio-economy, as well as the transportation system, predominantly depend on it. So the river is a lifeline of Barishal district. The river originates from Arial Khan River near Shayestabad and ends in Gajalia near Gabkhan channel. The total length of the river is about $160 \mathrm{~km}$ (DoE 2016). The maximum width between the banks of the river is $800 \mathrm{~m}$ (approx.) near Char Upen whereas $300 \mathrm{~m}$ is the minimum width near Barishal launch terminal as well as depth variation of Kirtankhola approximately $26 \mathrm{~m}$ to $9 \mathrm{~m}$ in the thalweg (Ahmed and Afrin 2016). This study was carried out at three unions of Barishal Sadar Upazila; Charkawa, Charbaria, and Charmonai (Fig. 1). The study area falls between $22^{\circ} 41^{\prime}$ and $22^{\circ} 45^{\prime}$ north latitudes and between $90^{\circ} 22^{\prime}$ and $90^{\circ} 27^{\prime}$ east longitudes (Fig. 1). The study area shows plane topography where the bank soil of the Kirtankhola River is mostly medium to fine-grained sand along with coarse to fine-grained sand and a small amount of silt and clay (Hasan et al. 2018). The Kirtankhola riverbank contains loosely compacted sandy soils with high moisture content and less cohesiveness (Hasan et al. 2018). This area is also highly influenced by the daily semi-diurnal tide. During the dry season, the tidal variation was about $1.5 \mathrm{~m}$ whereas 0.5 $\mathrm{m}$ in the wet season, $2 \mathrm{~m} / \mathrm{s}$ was the maximum velocity of the river as well (Ahmed and Afrin 2016). The variation of discharge during the high-water flow was about 4000 $\mathrm{m}^{3} / \mathrm{s}$ and during low water flow it was $3000 \mathrm{~m}^{3} / \mathrm{s}$ (Ahmed and Afrin 2016).

\section{MATERIALS AND METHODS}

\subsection{Data Used}

Comprehensive literature reviews were carried out at every stage of this study. Secondary data was collected from different scientific journals, articles, websites, newspapers, textbooks, satellite images, etc. The images of Landsat 4-5 TM C1 Level-1 of 2009 and Landsat 8 OLI/TIRS C1 Level-1 of 2019 were taken from USGS Earth Explorer (Table 1). Time series data of 10 years of the study area were collected from Google Earth Pro. Elevation profiles and two cross-sections were illustrated by Surfer 13 software. Arc GIS 10.4 Software was used for identifying amount of bank consumption as well as river shifting. 


\section{LOCATION MAP}

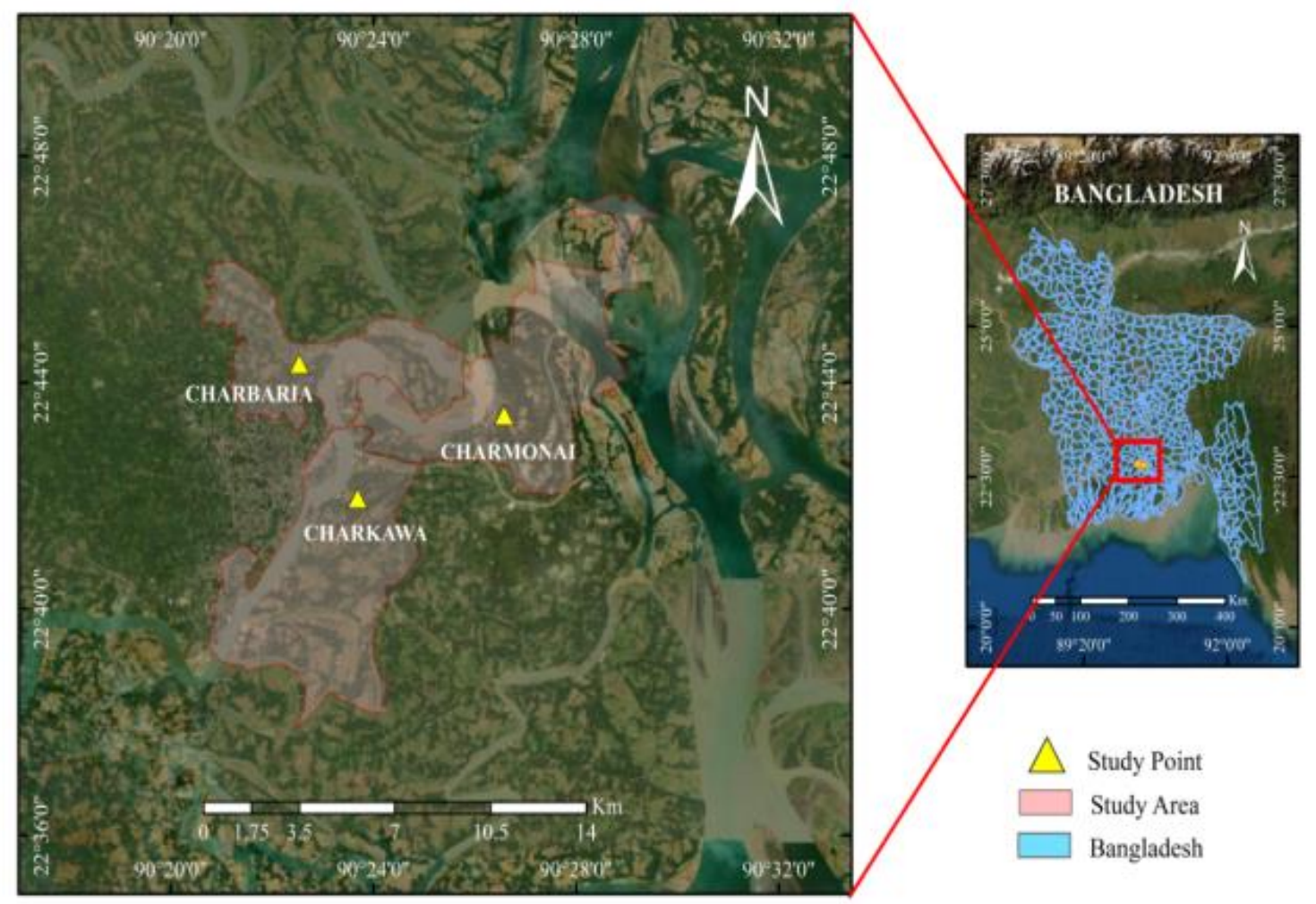

Figure 1. The study was carried out at three unions of Barishal Sadar Upazila; Charbaria, Charmonai, and Charkawa

Table 1. Landsat satellite images used for this study purposes

\begin{tabular}{ccccc}
\hline Satellite/ Sensor & $\begin{array}{c}\text { Spatial } \\
\text { Resolution(m)/Row/Path }\end{array}$ & Date of Acquisition & Spectral Bands $(\mu \mathrm{m})$ & Data Source \\
\hline $\begin{array}{c}\text { Landsat-8 } \\
\text { (OLI/TIRS) }\end{array}$ & $30 / 45 / 136$ & $23 / 11 / 2019$ & $\begin{array}{c}\text { B3 (Green): 0.53-0.59 } \\
\text { B5 (NIR): 0.85-0.88 }\end{array}$ & https://earthexplorer.usgs.gov/ \\
Landsat-5 (TM) & $30 / 45 / 136$ & $26 / 10 / 2009$ & $\begin{array}{c}\text { B2 (Green): 0.52-0.60 } \\
\text { B3 (NIR): } 0.77-0.90\end{array}$ & \\
\hline
\end{tabular}

\subsection{Satellite Images and GPS Data Analysis}

Current data about the number of active launch routes, the number of running steamers, and waterbus in Barishal were collected from different news reports and "www.barisal.govt.bd" website. Google Earth Pro software was also used to compare the number of steamers and boats in Barishal Launch terminal jetty between 2009 and 2019. A GERMIN eTrex-20 GPS device was used to obtain the average velocity data of running launches, waterbuses, and speed boats, etc., and made a data table contained the maximum and average velocity, total travel time, traveling distance, the name of the routes as well as investigated passenger ships (Table 2). Total of 15 launches and speed boats were investigated to collect data.

\subsection{Field Survey}

The study area was selected based on news reports, scientific articles as well as in situ observation of the affected area. Most significantly, the questionnaire was made in artless and explicit way so that the participants and volunteers could easily understand. A semistructured questionnaire survey was based on finding the real scenarios of the natural and anthropogenic causes of bank erosion as well as the status of local people migration. Total fifty respondents were collected from local people who are more or less affected by riverbank erosion. All participants independently expressed their point of view about the potential manmade and natural factors which are responsible for the disastrous bank erosion at their unions. Samples were collected randomly aiming so that outcomes become more vigorous. Finally, the most vulnerable points in the study area were picked up according to this field survey. 
Table 2. Name of the route and investigated steamers/launches running along Kirtankhola River in 2019, distance from Barishal, travel time, and maximum and average velocity of those launches and speed boats.

\begin{tabular}{|c|c|c|c|c|c|c|}
\hline SL & Name of Route & Name of Launch & $\begin{array}{l}\text { Total } \\
\text { Distance } \\
(\mathrm{Km})\end{array}$ & Travel Time (Hour) & $\begin{array}{l}\text { Maximum Velocity of } \\
\text { Launch/Boat }\end{array}$ & $\begin{array}{l}\text { Average Velocity of } \\
\text { Launch }\end{array}$ \\
\hline 1 & Dhaka-Barishal & M.V Suravi-9 & 161 & 6 hours 45 minutes & $32.17 \mathrm{Km} / \mathrm{h}$ & $23.85 \mathrm{Km} / \mathrm{h}$ \\
\hline 2 & Dhaka-Barishal & M.V Sundarban-10 & 161 & 6 hours 52 minutes & $32.65 \mathrm{Km} / \mathrm{h}$ & $23.40 \mathrm{Km} / \mathrm{h}$ \\
\hline 3 & Dhaka-Barishal & M.V Parabat-11 & 161 & 7 hours 15 minutes & $29.08 \mathrm{Km} / \mathrm{h}$ & $22.21 \mathrm{Km} / \mathrm{h}$ \\
\hline 4 & Dhaka-Barishal & M.V Kirtankhola-2 & 161 & 7 hours & $29.90 \mathrm{Km} / \mathrm{h}$ & $23 \mathrm{Km} / \mathrm{h}$ \\
\hline 5 & Dhaka-Barishal & M.V Kirtankhola-10 & 161 & 6 hours 35 minutes & $33.27 \mathrm{Km} / \mathrm{h}$ & $24.47 \mathrm{Km} / \mathrm{h}$ \\
\hline 6 & Dhaka-Barishal & Adventure-9 & 161 & 6 hours 28 minutes & $37.12 \mathrm{Km} / \mathrm{h}$ & $24.88 \mathrm{Km} / \mathrm{h}$ \\
\hline 7 & Dhaka-Barishal & M.V Green Line-2 & 161 & 5 hours 21 minutes & $41.51 \mathrm{Km} / \mathrm{h}$ & $30.08 \mathrm{Km} / \mathrm{h}$ \\
\hline 8 & Dhaka-Barishal & M.V Green Line-3 & 161 & 5 hours 15 minutes & $43.30 \mathrm{Km} / \mathrm{h}$ & $30.67 \mathrm{Km} / \mathrm{h}$ \\
\hline 9 & Dhaka-Barishal & M.V Manami & 161 & 6 hours 46 minutes & $34.80 \mathrm{Km} / \mathrm{h}$ & $23.78 \mathrm{Km} / \mathrm{h}$ \\
\hline 10 & Dhaka-Barishal & M.V Kuakata-2 & 161 & 6 hours 40 minutes & $35.10 \mathrm{Km} / \mathrm{h}$ & $24.17 \mathrm{Km} / \mathrm{h}$ \\
\hline 11 & Barishal-Ilisha & M.V Supersonic-5 & 46.78 & 4 hours 12 minutes & $16.33 \mathrm{~km} / \mathrm{h}$ & $11.61 \mathrm{Km} / \mathrm{h}$ \\
\hline 12 & Barishal-Hizla & M.V Inzam & 37.35 & 3 hours 8 minutes & $15.92 \mathrm{Km} / \mathrm{h}$ & $11.93 \mathrm{Km} / \mathrm{h}$ \\
\hline 13 & $\begin{array}{l}\text { Barishal-Bhola } \\
\text { (Veduria ghat) }\end{array}$ & M.V Awlad Express & 23.60 & 2 hours 35 minutes & $14.25 \mathrm{Km} / \mathrm{h}$ & $9.53 \mathrm{Km} / \mathrm{h}$ \\
\hline 14 & $\begin{array}{l}\text { Barishal-Bhola } \\
\text { (Veduria ghat) }\end{array}$ & Local Speed Boat & 23.60 & 40 minutes & $44.21 \mathrm{~km} / \mathrm{h}$ & $35.76 \mathrm{Km} / \mathrm{h}$ \\
\hline 15 & $\begin{array}{l}\text { Barishal-Bhola } \\
\text { (Veduria ghat) }\end{array}$ & Local Speed Boat & 23.60 & 45 minutes & $39.65 \mathrm{Km} / \mathrm{h}$ & $31.47 \mathrm{Km} / \mathrm{h}$ \\
\hline
\end{tabular}

\subsection{Evaluation of Erosion and Accretion}

The measurement of lost land and newly formed land from 2009 to 2019 was done separately for the two different banks (Table 3). River bank lines of two selected year were drawn and then the movement was detected in $\mathrm{kml}$ file format. Where the recent bank line entered through the past line that means erosion and where it comes away means accretion. Erosion and accretion amount was determined precisely. With the help of conversion tools of GIS, kml file was converted into a layer and a map was produced. Finally, an erosion-accretion diagram was delineated (Fig. 2).

\subsection{Channel Migration, River Flow Pattern and Cross-section}

River channel migration was identified by analyzing satellite images. The study used Landsat satellite images 4-5 TM C1 Level-1 and Landsat 8
OLI/TIRS C1 Level-1. Arc GIS 10.4 was used to make an unsupervised classification of the target area which depicted the river flow pattern. Surfer 13 software was used to draw river cross-sections through an illustration of the elevation profiles at selected points. This drawing process involves several steps. Firstly, geographic coordinate data of each point was collected by Google Earth Pro software in $\mathrm{kml}$ file format. Total six set of data was gathered from the study area. Every point has two data set, one is from 2009 and another contains data from the year of 2019. Secondly, the altitude values of these sites were updated by using GPS Visualizer and converted into GPX format. Further, these GPX files were processed and converted into CSV format by TCX and Microsoft Excel Office 2016 software. Finally, these data were plotted into Surfer 13 software to delineate contour maps as well as elevation profiles of each site (Fig. 3). 


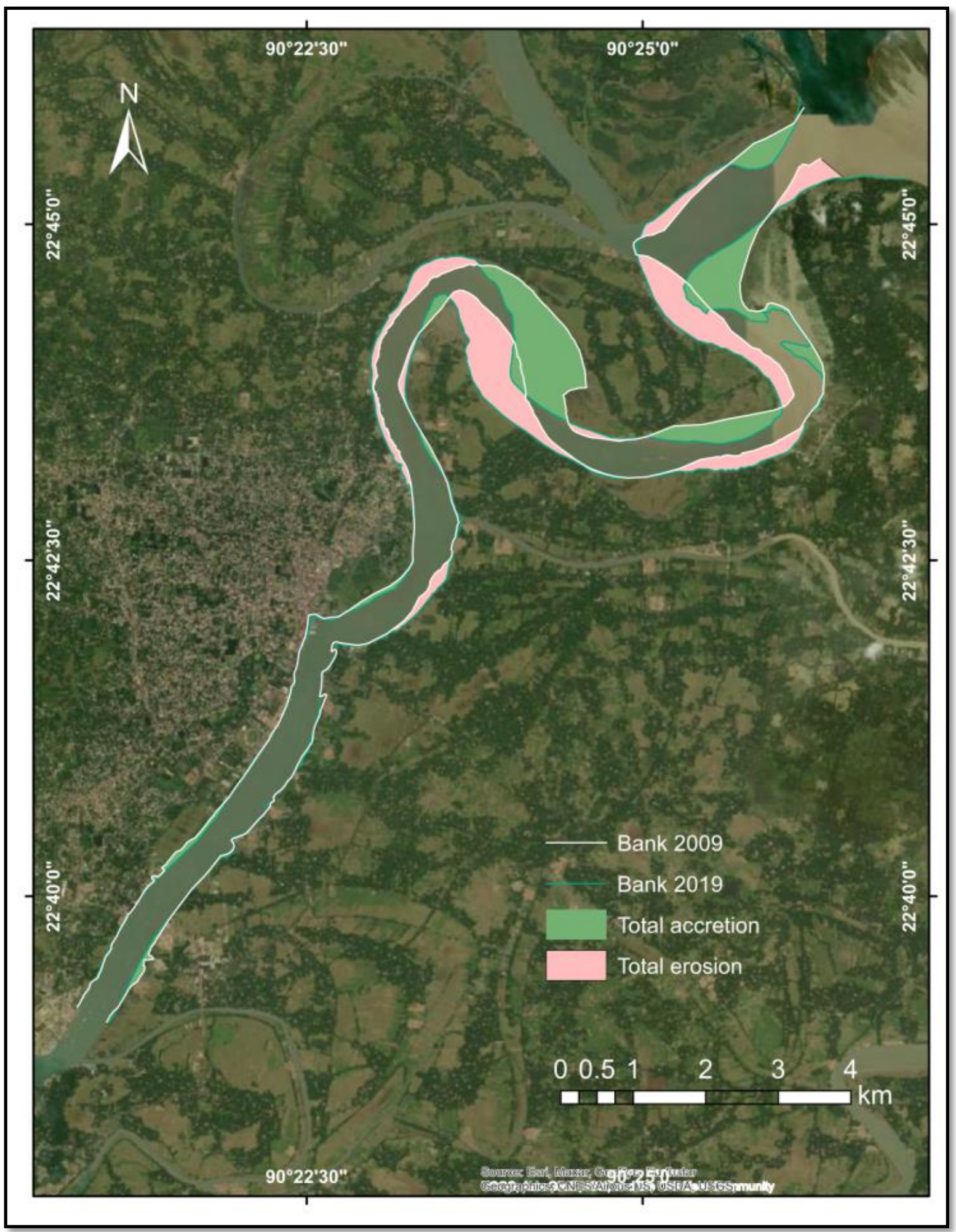

Figure 2. Map illustrates the amount of bank erosion and accretion of Kirtankhola River in the study area from 2009 to 2019

Table 3. Net erosion and accretion statistics of the Kirtankhola River, Barishal

\begin{tabular}{cccccc}
\hline $\begin{array}{c}\text { Time Duration } \\
\text { (year) }\end{array}$ & $\begin{array}{c}\text { Location } \\
\text { (Kirtankhola River) }\end{array}$ & $\begin{array}{c}\text { Erosion } \\
\text { (ha) }\end{array}$ & $\begin{array}{c}\text { Erosion Rate } \\
\text { (ha/year) }\end{array}$ & $\begin{array}{c}\text { Accretion } \\
\text { (ha) }\end{array}$ & $\begin{array}{c}\text { Accretion Rate } \\
\text { (ha/year) }\end{array}$ \\
\hline \multirow{2}{*}{$2009-2019$} & Right bank & 147.73 & 14.774 & 197.22 & 19.72 \\
& Left bank & 171.05 & 17.1 & 89.8 & 8.98 \\
& Total reach & 318.78 & 31.878 & 287.02 & 28.7 \\
\hline
\end{tabular}




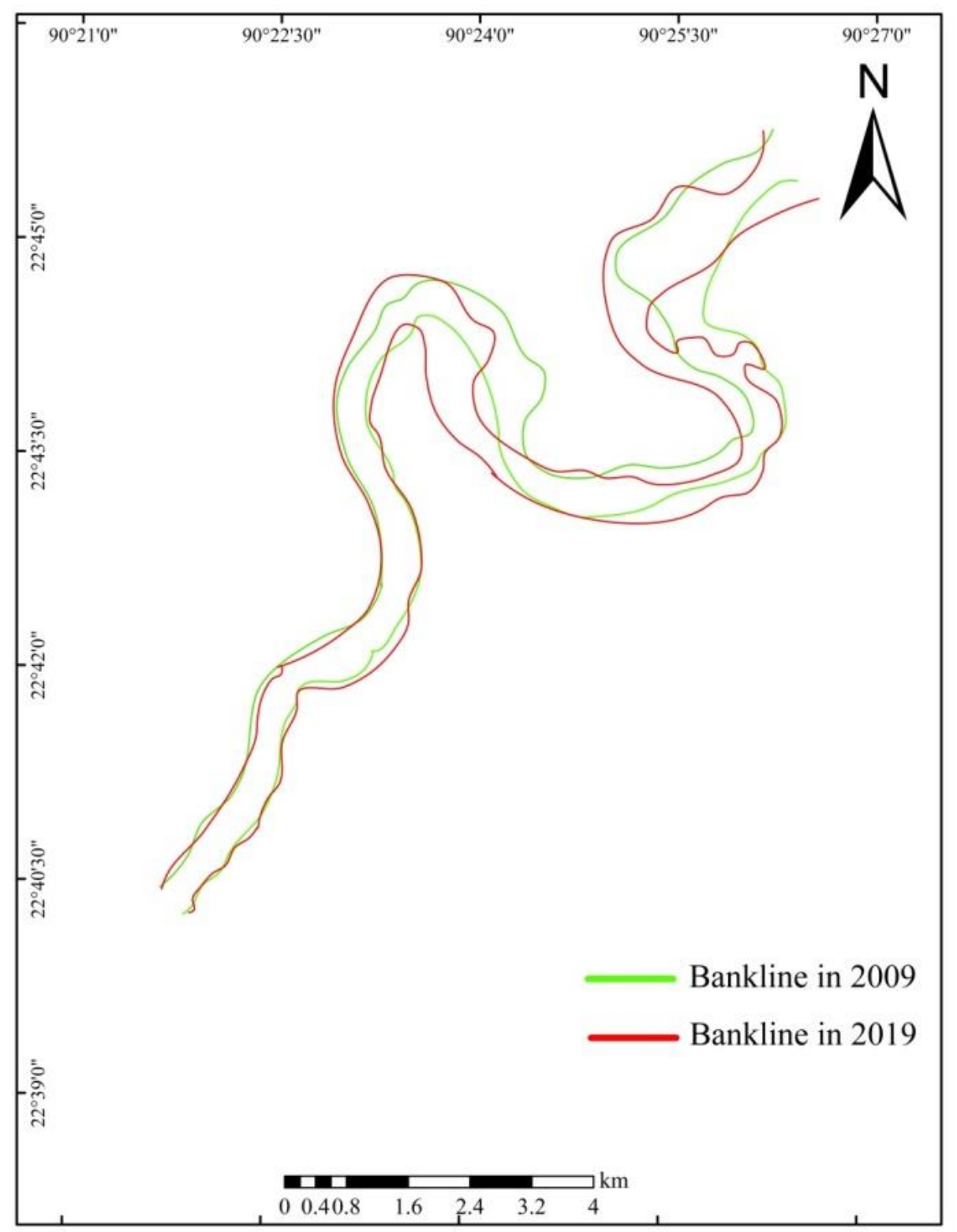

Figure 3. Diagram represents channel shifting over the study period, the red line representing the bank line in 2019 and green line is the bank line in 2009.

\subsection{Normalize Difference Water Index (NDWI)}

The satellite images of 26 October 2009 and 23 November 2019 were processed to visualize the riverbank erosion. Normalize Difference Water Index (NDWI) map was created to make a comparison of riverbank line of two different images. However, in this study, NDWI is used to differentiate the water body, vegetation, and open land in the study area.

This following formula has been used to make the NDWI map:

$$
N D W I=\frac{G R E E N-N I R}{G R E E N+N I R}
$$

NDWI values in between -1 to 1 indicate water body because of higher reflectance of NIR band than G band whereas, negative NDWI values indicate vegetation.

\section{RESULTS AND DISCUSSION}

\subsection{Morphological Changes of Kirtankhola River}

The amount of erosion and accretion in the study area from 2009 to 2019 was 318.78 hectare and 287.02 hectares respectively (Table 2). The river was eroding at a rate of 31.676 (ha/year) and accreting at 28.70 (ha/year). However, erosion was severe at the left bank but accretion was far more at the right. At the right bank, erosion was 147.73 hectare, whereas accretion was 197.22 hectare so the net gain of land was 49.49 hectare. In contrast, at the left bank, erosion was 171.05 hectare and accretion was 89.8 hectare so the net land loss was 81.25 hectare. Finally, the study showed that the overall erosion and the rate of erosion was more dominant than accretion and the rate of accretion and in terms of vulnerability, the left bank is more in danger (Fig. 2). 
Riverbank migration map (Fig. 3) illustrates the bank line movement from 2009 to 2019. This lateral movement is pronounced in the study area shown in Fig. 3. The river had been widening at the meandering zone adjoining to Chaekawa, Charbaria, and Charmonai unions due to tremendous bank consumption. This map also depicts how much of both banks of Kirtankhola are shifting throughout 10 years (Fig. 3). The shape of the Kirtankhola was being changed due to extensive erosion along with sediment deposition in the study area.

It is obvious from the comparison maps given in Fig. 4. Riverbank erosion was pronounced at investigated sites. A huge amount of land had already disappeared by the river and specifically the area adjacent to meander strongly affected by bank erosion (Fig. 4). Not only landform but also the difference of vegetation amount had been identified clearly from the comparison maps. At Charkawa point, erosion was prominent at the left bank, whereas accretion was occurred mainly at right bank (Fig. 4a,b). At the left, it can be seen that river has migrated to the land and a significant change of vegetation also visible. Finally, the river in 2019 at Charkawa was wider than in 2009 (Fig. 4;a,b).

Similarly, at Charbaria point a clear view of largescale erosion and accretion was shown (Fig. 4;c,d). The left bank which is the point bar had squeezed and turned into one-third of 2009. In contrast, the right bank had cut across the land area about $200 \mathrm{~m}$. Significantly, a new land area is also visible at the right bank (Fig. $4 ; c, d)$.

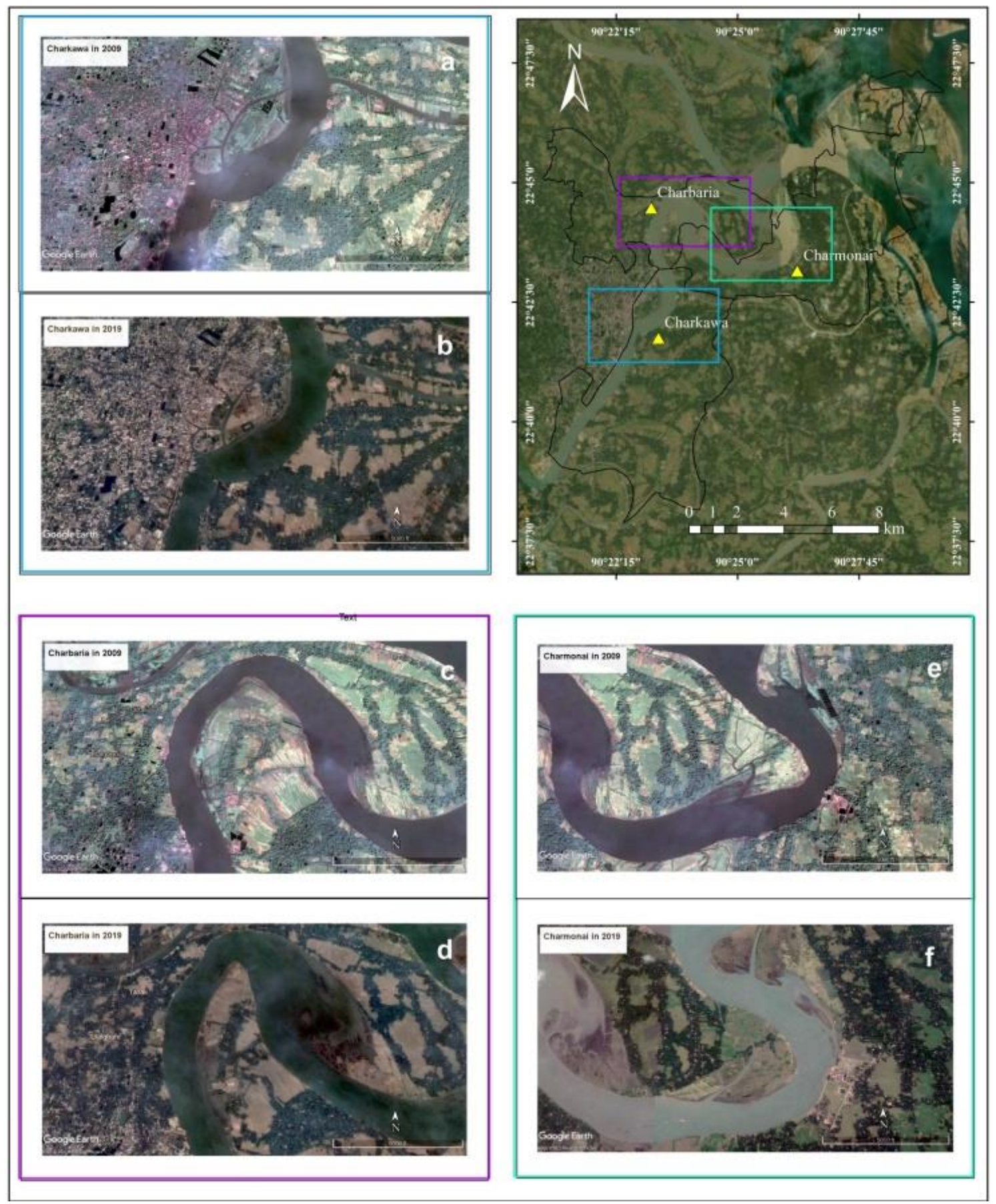

Figure 4. Comparison of changes of river banks at the Charkawa (a,b), Charbaria (c,d), and Charmonai (e,f) point between 2009 and 2019 
At Charmonai point, the most change visible at the right bank of the river where mostly accretion was occurred (Fig. 4; e, f). The amount of erosion is respectively less. However, the left bank is considerably constant. Neither noticeable erosion nor accretion was visible at the left side.

The normalize difference water index (NDWI) maps were depicted the distinction of Kirtankhola river water body migration, the amount of vegetation and open land areas between 2009 and 2019 (Fig. 5). From the maps, it is obvious that the water body area of the Kirtankhola River has been increasing due to severe bank erosion at Charbaria, Charmonai, but comparatively less increased at the Charkawa. On the other hand, open land has been increasing due to deforestation as well as sediment accumulation at point bars and some particular places along the river bank notably at Charmonai and Charbaria but at Charkawa union newly formed areas are relatively lower than the first two.

Elevation profile maps show the cross-sectional difference of the Kirtankhola River at Charkawa section (Fig. 6a, b). Here, the cut bank of the river cross-section at the right-hand side in elevation profile map is showing the bank slope is being steeper with time. Cut bank slope at the left side of Kirtankhola was comparatively gentle in 2009 than in 2019. In 2019, the river bed has become relatively wider than in 2009. Consequently, riverbank erosion is gradually changing the shape of the bank lines as well as the river bed of the Kirtankhola at Charkawa like the rest of the sections.

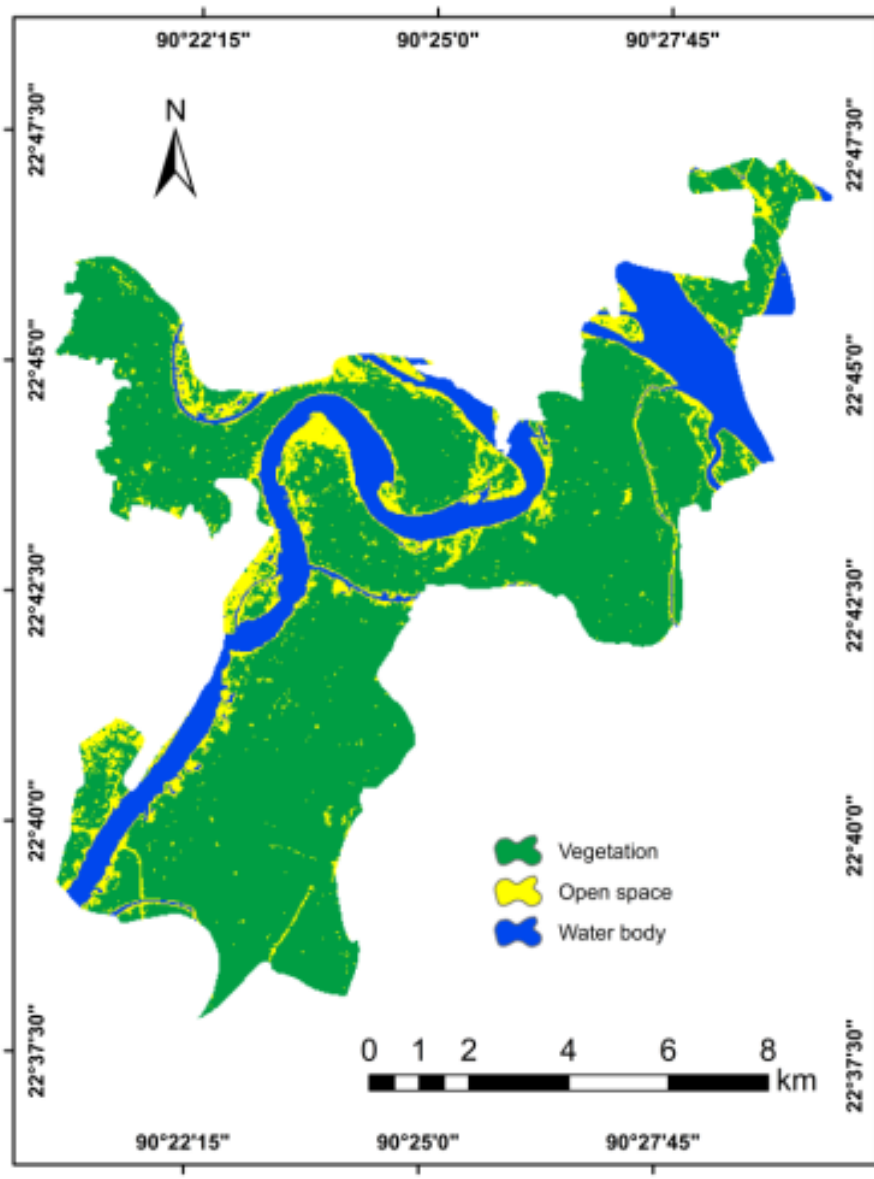

a) NDWI 2009

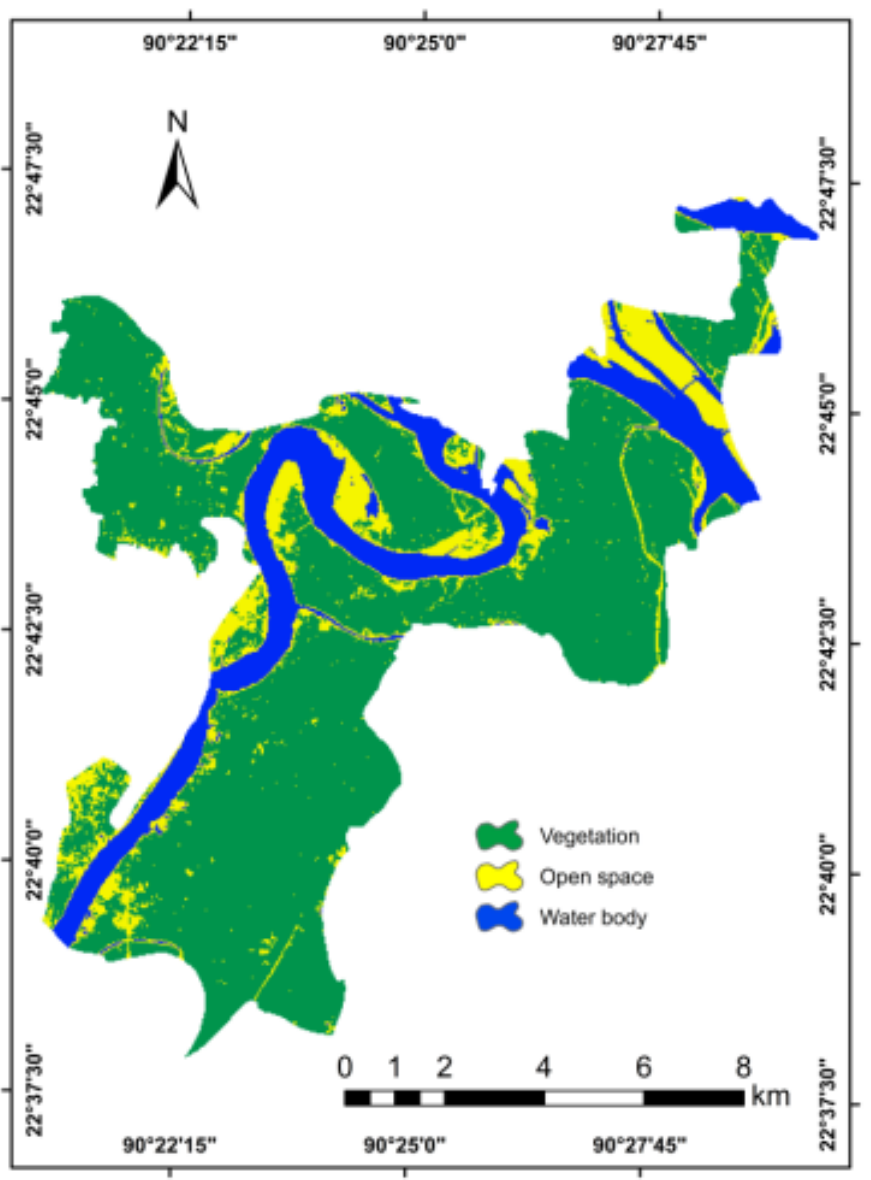

b) NDWI 2019

Figure 5. Normalize Difference Water Index (NDWI) Maps (a) NDWI in 2009 (b) NDWI in 2019. Map shows the difference of landforms,vegetation, and open land area at Charbaria, Charkawa and Charmonai respectively

Likewise, the elevation profile maps demonstrate the transformation of the cross-section at the Charbaria section (Fig. 6;c,d). Here in the contour maps, the blue occupied area indicates the water body. The red circled area in the contour map indicating the river crosssection. Significant change is identifiable from the elevation profile maps where in 2009 the cross-section was almost V-shaped and the cut bank at the right side had relatively less flat river bed, but in 2019 the river cross-section at a similar point is wider and flattered. The U-shaped channel indicates that, the river has become wider at this point due to bank erosion.
The change of cross-section of Kirtankhola River at Charmonai section is clearly identifiable in (Fig. 6; e, f). The river bed has become U-shaped in 2019 and the cut bank slope of the river at the left side has become steeper than 2009. In 2009 at the same point river cross-section was V-shaped. Elevation map at Charmonai also indicates the right bank or point bar has become more steady-state due to sediment deposition (Fig. 6; e, f). So, the change of shape of the cross-section and bank slope indicates the horrific riverbank erosion at the Charmonai section. 


\subsection{Questionnaire Survey}

The questionnaire survey shows that about $61 \%$ of local affected people opined that boat generated waves are the anthropogenic key factor that triggered bank erosion in the study area, about $15 \%$ of them commented deforestation is the key factor. Besides, around $13 \%$ and $11 \%$ of people believed that excessive sand extractions, as well as river mismanagement, are the man-made key factor that facilitated bank erosion.

Meanwhile, the bar diagram is demonstrating the number of displacements of the respondents in their life so far due to acute bank erosion (Fig. 7). Forty respondents out of 50 had experienced migration more than once and two of them had to shift 7 times. The 6, 5 and 4 respondents retreated 4, 5, and 6 times respectively owing to bank erosion (Fig. 8).
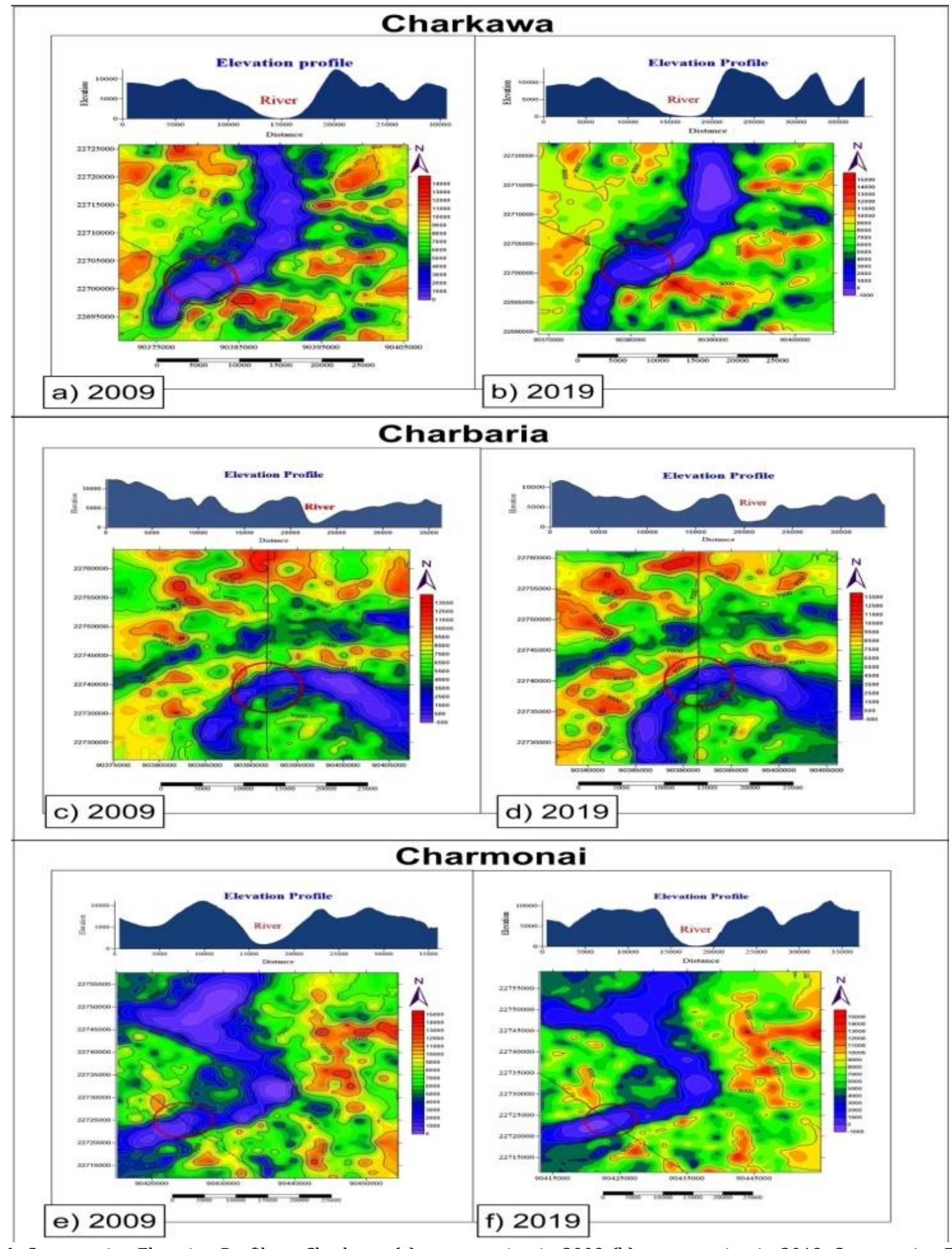

Figure 6. Comparative Elevation Profile at Charkawa (a) cross-section in 2009 (b) cross-section in 2019. Comparative Elevation Profile at Charbaria (c) cross-section in 2009 (d) cross-section in 2019. Comparative Elevation Profile at Charmonai (e) cross-section in 2009 (f) cross-section in 2019 of Kirtankhola river. 


\subsection{Factor Accelerating Bank Consumption}

Kirtankhola is a meandering river and there are three meanders in our study area. Every union contains one of them. The cut banks at Charkawa,Charbaria, and Charmonai sections are often displaced due to boatinduced strong water waves. Powerful centrifugal forces are formed when a launch or water bus cross the meander (Fig. 9). As meander is a semicircular path along with the velocity of the running boat, the circle radius deduces the formula of centrifugal force formulated by Newton.

The formula of centrifugal force is:

$$
F=m \omega^{2} r
$$

The centrifugal force is denoted by $\mathrm{F}, \mathrm{m}$ is the mass of the rotating object, $\omega$ is the angular velocity of the moving object and $r$ is the distance from the center of the circle.

Hence, the centrifugal force is proportional to the mass of the object, square of angular velocity, and radius or distance from the origin. Centrifugal force is zero at the origin where $r=0$. At meander or the edge of the circle, the r-value could be reached up to the maximum. When a launch or speed boat passing through a semicircular meander with high velocity, it forms a mighty centrifugal force that results from powerful hydraulic waves that hit repeatedly and forcefully on the banks of the river and facilitate bank erosion.

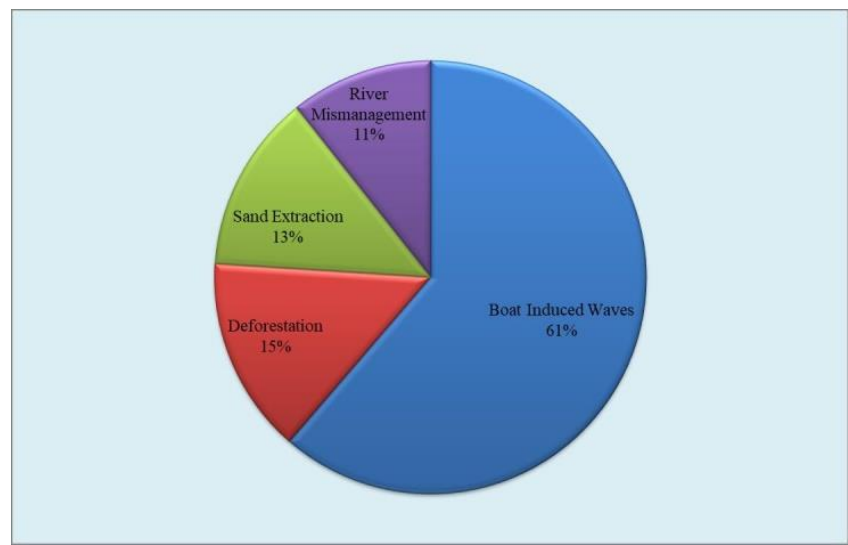

Figure 7. Feasible anthropogenic key factors based on questionnaire survey data.

[Participants were asked the question: "What are the natural and anthropogenic causes of the riverbank erosion?"]

Satellite images show the remarkable change at Barishal Launch Terminal and nearby Barishal Speed boat terminal (Fig. 10). The number of large and small size motorized steamer, as well as speed boat, has been increased dramatically with time (Islam and Degiuli, 2015). In the google image of 2009 a small number of launches were standing at the terminal jetty, among those three large-size launches are noticeable, whereas in 2019 satellite image shows the number of both large and small size launches has been climbing up and at least seven large scale launches are standing at the jetty. A similar scene is salient in the satellite image of 2019 where the number of speed boats has been increased at the speed boat terminal.

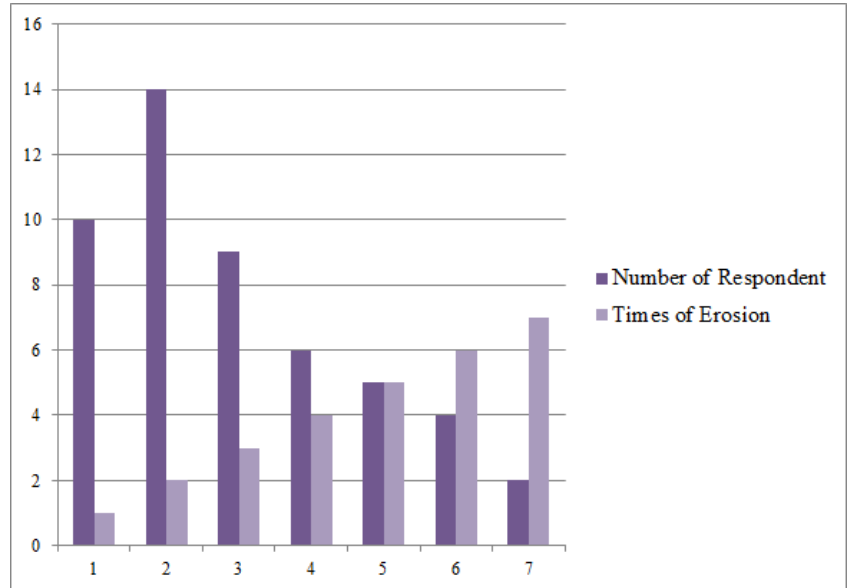

Figure 8. Times of land loss due to bank erosion experienced by the respondents in their entire life.

[Participants were asked the question: "How many times you have faced riverbank erosion in your entire life?"]

At present Kirtankhola has become busy river traffic. Everyday 22 large sized launches having capacity of carrying 1200-1500 passenger and more than 50-speed boats are actively running through Kirtankhola River (www.barisal.govt.bd). According to rules for safe and fast boating in Netherland, the speed of inland river vessels/launches should be below $20 \mathrm{~km} / \mathrm{h}$. But in the Dhaka-Barishal route, most of the launches and water buses along with local speed boats have a velocity over $30 \mathrm{~km} / \mathrm{h}$ resulting in strong hydraulic waves. Due to poor navigability in the Kirtankhola river these swiftmoving launches, water bus and speed boats often move along relatively deeper cut bank side and result from powerful waves repeatedly hit on unconsolidated cut banks and making the river banks more vulnerable to deteriorate.

\section{CONCLUSION}

The riverbank community of Kirtankhola River, Barishal is one of the disastrous localities due to various natural calamities of which riverbank erosion is an important one that is affecting and displacing millions of bank people. In addition, the situation could be even deteriorated by direct and indirect human influences and recently it's also imposing danger on the existence of many infrastructures near to the bank. In this study found a high rate of land loss on both side of the riverbank. The total erosion in the study area within ten years was 318.78 ha whereas the accreted new land amount was 287.02 ha. Most of the victims pointed out that strong currents produced by high-speed vehicles are accelerating this erosion. About $80 \%$ of the questionnaire participants have been affected more than one time. In addition, the newly formed lands in not being well distributed among the victims. As a result, many of them have to move to another place for their livelihood.

The study used GIS and RS techniques and there may present some uncertainties. But these methods are really very useful to do this kind of works. The results that are obtained through research may help the authorities to take decisions related to bank protection in Barishal and to develop the socio-economic and 
livelihood status in the studied area. Still some detailed sedimentological and geotechnical analysis is needed to evaluate the vulnerability of Kirtankhola River.

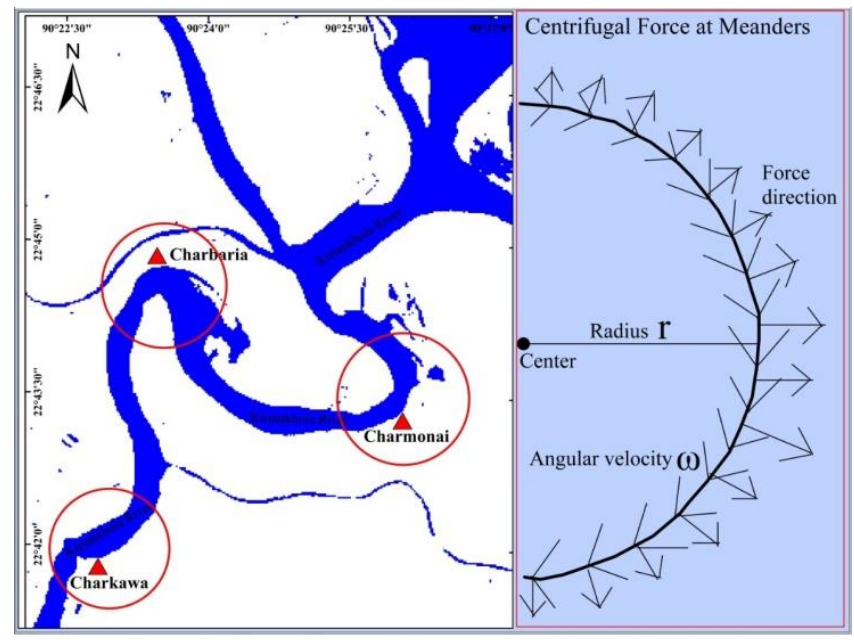

Figure 9. Mechanism of generating Centrifugal force by water vessels at meanders.

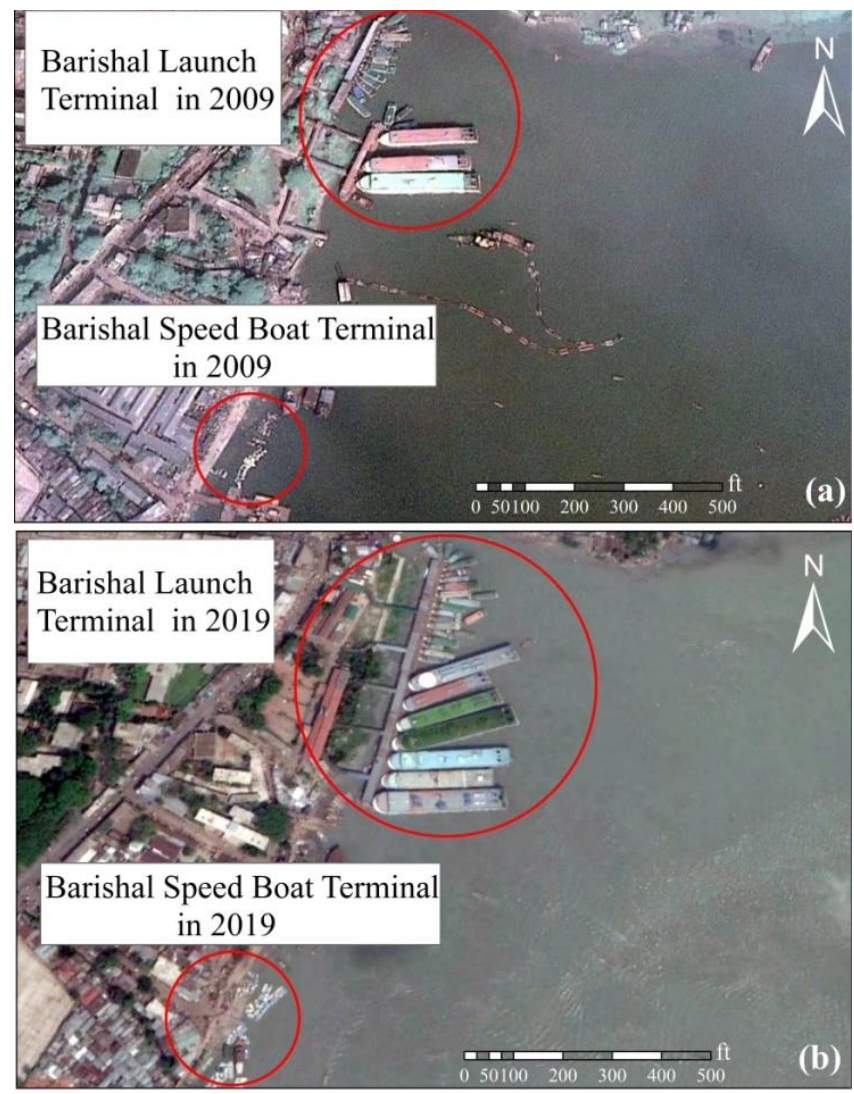

Figure 10. Satellite images of Barishal launch and speed boat terminal (a) image taken in 2009 (b) image taken in 2019. The ted circled area in satellite images indicates the comparative launch and speed boat number in 2009 and in 2019.

\section{ACKNOWLEDMENT}

The corresponding author greatly thankful to Department of Geology and Mining, University of Barishal, USGS authorities and Government of Bangladesh for technical support, availability of data through the entire study. The author specially thanks to
MAS and MRR for reviewing the manuscripts, their valuable remarks and preparing for final draft.

\section{Author contributions}

Shaikh Ashikur Rahman: Conceptualization, Methodology, Software Interpretation, Writing-Original draft preparation. Md. Muzahidul Islam: Conceptualization, Methodology, Software Interpretation, Writing-Original draft preparation. Md. Abdullah Salman: Visualization, Investigation, WritingReviewing and Editing. Muhammad Risalat Rafiq: Visualization, Investigation, Writing-Reviewing and Editing.

\section{Conflicts of interest}

The authors declare no conflicts of interest.

\section{REFERENCES}

Ahmed K R \& Afrin S (2016). Physical Modelling for the Improvement of Barisal Harbor Area. Tech. J. River Res. Inst. 13(1): 11-25, 2016 (October), ISSN: 16069277, 13(1), 11-25.

BDoE (Department of Environment) (2016). River Water Quality Report 2015. Ministry of Environment and Forest, Government of People's Republic of Bangladesh. Natural Resource Managment Section, Department of Environment., 50.

Billah M M (2018). Mapping and monitoring erosionaccretion in an alluvial river using satellite imagery The river bank changes of the Padma River in Bangladesh. Quaestiones Geographicae, 37(3), 87-95. doi.10.2478/quageo-2018-0027

Hasan M, Quamruzzaman C, Rahim A, Hasan I, Methela N J \& Imran S A (2018). Determination of River Bank Erosion Probability: Vulnerability and Risk in Southern Shoreline of Bangladesh. International Journal of Energy and Sustainable Development, 3(3), 44-51.

Hassan S \& Akhtaruzzaman F M (2010). Environmental Change Detection of the Padma River in the NorthWestern part of Bangladesh using Multi-date Landsat Data. Proc. of International Conference on Environmental Aspects of Bangladesh (ICEAB10), (October), 193-195.

Hohensinner S, Hauer C \& Muhar S (2018). River Morphology, Channelization, and Habitat Restoration. Riverine Ecosystem Management, 41-65. https://doi.org/10.1007/978-3-319-73250-3_3

Islam M F \& Rashid A B (1970). Riverbank erosion displacees in Bangladesh: need for institutional response and policy intervention. Bangladesh Journal of Bioethics, 2(2), 4-19. https://doi.org/10.3329/bioethics.v2i2.9540

Islam M R \& Degiuli N (2015). INVESTIGATION OF THE CAUSES OF MARITIME ACCIDENTS IN THE INLAND WATERWAYS OF BANGLADESH. 66(1).

Joshi C, Leeuw J De \& Duren I C Van (2002). Remote Sensing and Gis Applications. GeoInformation Science, 2(Graph 1), 669-677. 
http://citeseerx.ist.psu.edu/viewdoc/download?doi $=10.1 \cdot 1.138 .2861 \& a m p ; r e p=r e p 1 \& a m p ; t y p e=p d f$

Khan I, Ahammad M \& Sarker S (2014). A study on River Bank Erosion of Jamuna River using GIS and Remote Sensing Technology. International Journal of Engineering Development and Research, 2(4), 23219939.

Mahmud I, Mia A J, Islam A, Peas M H \& Farazi A H (2020). Assessing bank dynamics of the Lower Meghna River in Bangladesh: an integrated GIS-DSAS approach.

Mazumdar, N., \& Talukdar, B. (2018). Assessment of River Bank Erosion Potential in Brahmaputra River in Lower Assam Region Using Modified Rosgen 's Bank Erosion Hazard Index Method. 08(8), 21-27.

Nahar, N. (2015). Causes of River Bank Erosion, Its Effects on Life and Livelihood and Nature of Aids: A Case Study on Habashpur Union. 12, 85-98.

Nanson G C, Von Krusenstierna A, Bryant E A \& Renilson M R (1994). Experimental measurements of riverbank erosion caused by boat-generated waves on the gordon river, Tasmania. Regulated Rivers: Research \& Management, 9(1), 1-14. https://doi.org/10.1002/rrr.3450090102

Noel R. Oswalt, Claude N. Strauser (1983) Prototype Experience and Model Studies of Navigation Effects on Inland Waterways. American Society of Civil Engineers
Rabbi H, Saifullah A S M, Sheikh S, Sarker M H \& Bhowmick A C (2013). Study on River bank Erosion and its Impact. 2(2), 36-43.

Salman M A, Hasan S M R, Ahmed S, Tahsin M \& Khan N (2018). Shoreline Change Rate along the Southern Coast of Bangladesh due to Climate Change using Remote Sensing \& ArcGIS Technology. IJETAE. Volume 8, Issue 3, March 2018.

Sarkar A, Garg R D \& Sharma N (2012). RS-GIS Based Assessment of River Dynamics of Brahmaputra River in India. Journal of Water Resource and Protection, 04 (02),63-72. https://doi.org/10.4236/jwarp.2012.42008

Thakur P K, Laha C \& Aggarwal S P (2012). River bank erosion hazard study of river Ganga, upstream of Farakka barrage using remote sensing and GIS. Natural Hazards, 61(3), 967-987. https://doi.org/10.1007/s11069-011-9944-z

Umitsu M (1993). Late quaternary sedimentary environments and landforms in the Ganges Delta. Sedimentary Geology, 83(3-4), 177-186. https://doi.org/10.1016/0037-0738(93)90011-S

Waterways I, Regulation P, Navigation R, Regulations P, n.d. Rules for safe and fast boating. 